\title{
STUDIA CHRYSOSTOMICA
}

Aufsätze zu Weg, Werk und Wirkung des Johannes Chrysostomos (ca. 349-407)

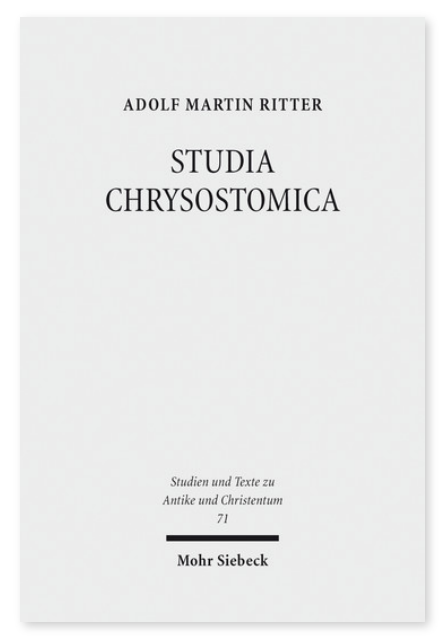

2012. XXIII, 233 Seiten. STAC 71

ISBN 978-3-16-152277-2

DOI 10.1628/978-3-16-152277-2

eBook PDF 89,00€

ISBN 978-3-16-152035-8

fadengeheftete Broschur 89,00€
Die 13 Studien über Johannes Chrysostomus (ca. 349-407), dem bereits die Göttinger Habilitationsschrift Adolf Martin Ritters gewidmet war, sind seit 1969 entstanden und die meisten seit 1971 veröffentlicht worden; die erste und die letzte waren bislang unveröffentlicht. Sie beleuchten, nicht unkritisch, eine der Lichtgestalten der Kirchengeschichte, und das unter ganz unterschiedlichen, nicht zuletzt methodologischen, Aspekten. Dem Autor ist vor allem an dem Forschungsgespräch gelegen, das oft genug in Ansätzen stecken bleibt, daher nimmt dieses in den Studien einen breiten Raum ein. Während die teilweise schon vor langer Zeit veröffentlichten Studien meist in der Substanz unverändert vorliegen, ist die Forschungsdiskussion (Sozialethik, Verständnis des Mönchtums bei Chrysostomus) an besonders strittigen Punkten bis in die Gegenwart fortgesetzt worden.

Adolf Martin Ritter Geboren 1933; Studium der Ev. Theologie in Marburg, Heidelberg, Göttingen und Athen; 1962 Promotion; 1970 Habilitation; seit 1981 Ordinarius für Historische Theologie in Heidelberg; seit 1999 emeritiert; 2000 Dr. h.c. Cluj-Napoca (Klausenburg); 2002 Dr. h.c. Oradea (Großwardein).

https://orcid.org/0000-0003-0507-3391

etzt bestellen:

https://mohrsiebeck.com/buch/studia-chrysostomica-9783161522772?no_cache=1

order@mohrsiebeck.com

Telefon: +49 (0)7071-923-17

Telefax: $+49(0) 7071-51104$ 